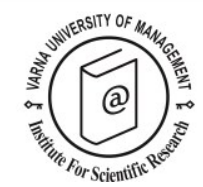

\title{
Dashper, K. (Ed.) (2014) Rural Tourism: An International \\ Perspective. Cambridge Scholars Publishing, \\ ISBN: 978-1-4438-6677-4, 423 pp.
}

\author{
Reviewed by Irena Erbakanova ${ }^{1}$
}

Received: 15/05/2016

\begin{abstract}
1 Varna University of Management, 13A Oborishte str., 9000 Varna, Bulgaria; email: irena.erbakanova@vumk.eu
\end{abstract}

(C) 2016 Varna University of Management. All rights reserved

Citation Li Dashper, K. (Ed.) (2014) Rural Tourism: An International Perspective. Cambridge Scholars Publishing, ISBN: 978-1-4438-6677-4, 423 pp. Reviewed by Irena Erbakanova, European Journal of Tourism Research 14, pp. 140-141

Rural Tourism: An international perspective is a very promising title. After going through the chapters it is pleasantly surprising to actually see that the book covers rural regions and areas in countries and islands like Sweden, New Zealand, France, South Australia, Estonia, India, Hawaii, Wales, Botswana, Sri Lanka, Tanzania, Peru, Denmark, Peninsula Malaysia, South Africa, Buenos Aires, Fair Isle, Norway and Cyprus. Moreover, instead of repeating old theories it actually focuses on contemporary, under-researched areas for rural tourism such as the growth, impact, issues and scope of this phenomenon and how globalization changed the way it is perceived in 2014.

This collection of case studies comprises of introduction and 21 chapters divided in 5 key themes defining the rural through tourism; rural tourism experiences; rural tourism in developing countries; collaboration and conflict in rural tourism; and rural tourism and regional development.
The first part of the book covers the definitions of "rural" separated by the application of different measures. It focuses on defining not rural tourism as a concept but the various ways in which tourism impacts on the understanding of the rural and ruralities. Chapter 1 by Peter Möller, Maria Thulemark and Christina Engström for example questions the divisions between 'rural' and 'urban' and the role tourism plays in maintaining or breaking down these divisions. The chapter involves very good contemporary discussions over the rural tourism. The focus of Chapter 2 is again on land/area use and the authors - Michael Mackay, Harvey C. Perkins and C. Nicholas Taylor, give an example of the emergence of a global multifunctional countryside in which tourism plays a crucial role. Hélène Ducros (Chapter 3 ) explores the changes in the ideas of what rural is and how the rural product can be repackaged so to attract tourists to the countryside. It is a very good example of an excellent practice gone global. The last chapter of this section as stated by the authors Rosie Roberts, Jodie George and 
Li Dashper, K. (Ed.) (2014) Rural Tourism: An International Perspective. Cambridge Scholars Publishing, ISBN: 978-1-44386677-4, 423 pp. Reviewed by Irena Erbakanova, European Journal of Tourism Research 14, pp. 140-141

Jess Pacella includes an exploration of the representation and construction of placebased identities through rural festival practices.

Part two of the book focuses mainly on the perspectives of locals and tourists when they experience rural tourism. In this section there are 2 outstanding chapters - Chapter 5 on staging sensescapes for rural experiences in Estonian farm tourism enterprises by Ester Bardone and Maarja Kaaristo and Chapter 7 by Saleh Azizi and Mary Mostafanezhad on the phenomenology of worldwide opportunities on organic farms (WWOOF). Both case studies are very applicable in terms of practice and can be given in a reading list for students.

The same applies for all four chapters (9 to 12) in section three 'Rural tourism in developing countries' the contributors Monkgogi Lenao, Fazeeha Azmi, Emmanuel Sulle, Holti Banka, Janemary Ntalwila and Jane Carnaffan discuss different rural tourism initiatives in the developing countries Botswana, Sri Lanka, Tanzania and Peru and the extent to which the development of rural tourism actually benefits local communities.

Part four (Chapter 13 to Chapter 16) actually goes beyond rural tourism as it discusses, probably not intentionally, many aspects on management and marketing of tourism destinations and the basic problems that might occur in terms of the collaboration and conflict (and specifically for this book this would be only in rural areas).

The last section of the book, as stated by the editor Katherine Dashper, discusses how different niche tourism offerings are being developed and promoted by different regions in attempts to differentiate themselves within the global tourism market. The case studies here are very various in terms of niche products and location, Butler (Chapter 17) discusses bird watching in Fair Isle, followed by the case study of Vafadari, Cooper and
Nakamura (Chapter 18) on rural tourism and Satoyama (Japan). Anne Buchmann (Chapter 19) analyses film tourism in rural New Zealand and reveals how film and rural tourism can be linked. Rhys Evans and Sylvine Pickel Chevalier (Chapter20) write about equine tourism in France, and the final Chapter 21 by Vassilios Ziakas and Nikolaos Boukas discusses rural island tourism in Troodos (Cyprus).

Although the chapters are divided in 5 parts there are case studies that fit not only the part they are in but also others. The methodologies used in the case studies are very well justified with few exceptions. Most case studies in this collection are applicable to a wider scenario not only for the studied region. From a research perspective the book critically evaluates various concepts and issues related with rural tourism and provides directions for future research. From a tourism practitioners' perspective, the book is written on a very comprehensible language, which makes it very easy to understand by practitioners. Furthermore, it gives very good ideas for development of rural tourism in various landscapes and areas both developed and underdeveloped; it deals as well with major challenges faced by various stakeholders in rural tourism and the challenges and good practices in the application of programs and projects to sustain landscapes, heritage and cultures and to alleviate poverty. From a pedagogical perspective the book is very suitable for researchers, postgraduate and last year undergraduate students, rather than for introductory tourism courses on undergraduate level, because they need knowledge on what tourism is so they can understand and operate with this book. It is an excellent choice though to support courses on special interest tourism, tourism landscapes and current issues in tourism. 